\title{
INFLUENCE OF CHAPLAINCY ON PREPARATION AND EXECUTION OF OPERATIONS
}

Stevica S. Karapandžin

Ministry of Defence of the Republic of Serbia, Media Centre "Odbrana"

This papers deals with one of the segments which can contribute

to development and enhancement of the military strength of the Serbian Armed Forces in operations by its positive influence mainly on moral component. The newly established chaplaincy in the Serbian Armed Forces is the aforementioned segment. The author states the concrete possibilities of the influence on planning, preparing and executing an operation in all its phases with an emphasis on doctrinal provisions. It means that the imperative is not development of the theological thought, but contribution to further doctrinal regulation of operations, improvement of moral component, enhancement of the total military strength of the Serbian Armed Forces and improvement of the operational art as one of the defence sciences. This paper serves as a short reminder of general issues of the Serbian Armed Forces operations with an emphasis on the role of chaplaincy in increasingly present multidimensional operational environment with focus on the link to social and time dimension. There are several short comparative analyses in order to explicate chaplaincy in planning, preparing and executing operations. The first one is the intensity analysis of three parallel activities, which are different according to its pith. These are the activities conducted during all three phases of the Army operations: combat, CIMIC and chaplaincy. The second one is the analysis of intensity of chaplaincy activities in operations phases whereas the third analysis is related to predominant types of their execution depending on operation phase. The paper expresses personal views with the aim to focus attention to the need and potential directions of further doctrinal and by-law development of this field. Concretely, it is necessary to upgrade the set of doctrinal documents in the field of operations, service, CIMIC and human resources management doctrines. Furthermore, it is necessary to elaborate procedures of work of military chaplains in commands and headquarters in operations planning process, and the level of their implementation should be enhanced through professional development and training of officers.

Key Words: operations, chaplaincy, CIMIC, military chaplains 


\section{Introduction}

The military strength of the Serbian Armed Forces consists of three mutually connected components: physical, conceptual and moral. The term mutually connected stresses the fact that in case of absence of one of them we could not talk about the military strength, which highlights the importance not only of each component individually, but their cumulative qualitative and quantitative influence. The moral component is particularly interesting for analysis, not only due to its significance, sensitivity and tendency to sudden changes, but because it was and still is the greatest unknown for a potential enemy. Without the moral component, the physical and conceptual ones do not have strength and completely lose the point. It is possible to contribute to development and enhancement of the military strength of the Serbian Armed Forces in contemporary operations by chaplaincy activities and a positive influence on the moral component, taking into account the fact they are conducted in conditions of rather multidimensional operational environment. It is expected that type and intensity of such activities greatly depend on the social and time dimension of operational environment, kind and phase of operations, and the scope of CIMIC activities and actors.

Having in mind characteristics of contemporary conflicts, a high level of dynamics characterized by contemporary operations, a wide variety of possible actions and a rich diversity of spiritual capacities at traditional churches and religious communities disposal from dogmatic aspect, and rather high percentage of the Serbian Armed Forces members declared as believers, it is expected that chaplaincy can have a positive effect on planning, preparing and executing operations. ${ }^{1}$

\section{Chaplaincy in operations}

Military chaplains participate in planning, preparing and executing operations. Moreover, restrictions connected to their engagement in some operations defined by the by-law regulation such as information and psychological operations are related exclusively to their engagement in performing main tasks of the aforementioned operations. In other words, the stated does not exclude spiritual care for the armed forces members engaged in those operations and includes only protective component of its own forces. Furthermore, from the aspect of participation of military chaplains in operations, it is important to stress their non-combatant status. Actually, these are members of the armed forces recognized by the Geneva Convention and treated as one of the protected categories in the rank of medical personnel, the wounded, civilians, etc. ${ }^{2}$

At an operational and tactical level military chaplains are directly subordinated to commanders and by upgrading the by-law regulation, which stipulates operational planning in the Serbian Armed Forces, as well as by development of standard operating procedures, it is possible to enhance modalities of their cooperation with officers responsible for moral and psychologists within groups which are formed in headquarters of the forces that execute an operation. ${ }^{3}$ Today

\footnotetext{
${ }^{1}$ Stevica S. Karapandzin, Chaplaincy in SAF, influence on Army operations, Media Centre „Odbrana”, Belgrade, 2015, p 11.

${ }^{2}$ Convention (III) related to the Treatment of Prisoners of War. Geneva, $12^{\text {th }}$ August 1949 , http://www.icrc.org/ihl//NTRO/375?OpenDocument, Internet, 08/03/2014.

${ }^{3}$ Guide for operational planning and work of commands in the SAF, Serbian Armed Forces General Staff, document of Planning and Development Department (J-5) Internal No. 3498-36, $16^{\text {th }}$ December 2013, Belgrade, p. 118.
} 
some defence sciences do not treat only military issues during operations because in their planning, preparation and execution both in peace and state of emergency and war there are numerous other non-armed and non-military factors, whose engagement affects the success of operations. Today we have multidimensional operational environment as one of the most significant characteristics of operations during which chaplaincy activities are conducted among others. From the point of view of this paper the social and time dimension are interesting out of the dimensions of operational environment defined by the Operations Doctrine of the Serbian Armed Forces (physical, time, political, social, economic, technological, information, military).

The social dimension represents the public opinion and its relation to an operation. The conditions which have to be met in order to have the favourable social component is respect of the international humanitarian law, legitimacy of the selected targets, provision of support for fulfilling objectives of operations and CIMIC in the area of an operation.

Undoubtedly, chaplaincy has its role in fulfilling certain number of the aforementioned conditions in operations. The relation of chaplaincy and legitimacy of the selected targets and CIMIC, as well as the effect of the time dimension, will be dealt with in greater detail later in the following text. As far as provision of support for fulfilling objectives of operations is concerned, chaplaincy does not exert an influence which would be interesting for analysis.

An operation is conducted in three phases: 1) preparation phase; 2) execution phase; 3) stabilization and disengagement phase. Chaplaincy activities are focused on constant coordination with activities carried out in all three phases of operations as their religious support in order to contribute to enhancement of its military strength. Therefore, focus should be on three short analyses.

The first one is the intensity analysis of three parallel activities, which are different and conducted during all three phases of combat operations: 1) combat activities; 2) CIMIC activities and 3) chaplaincy activities (Picture 1).

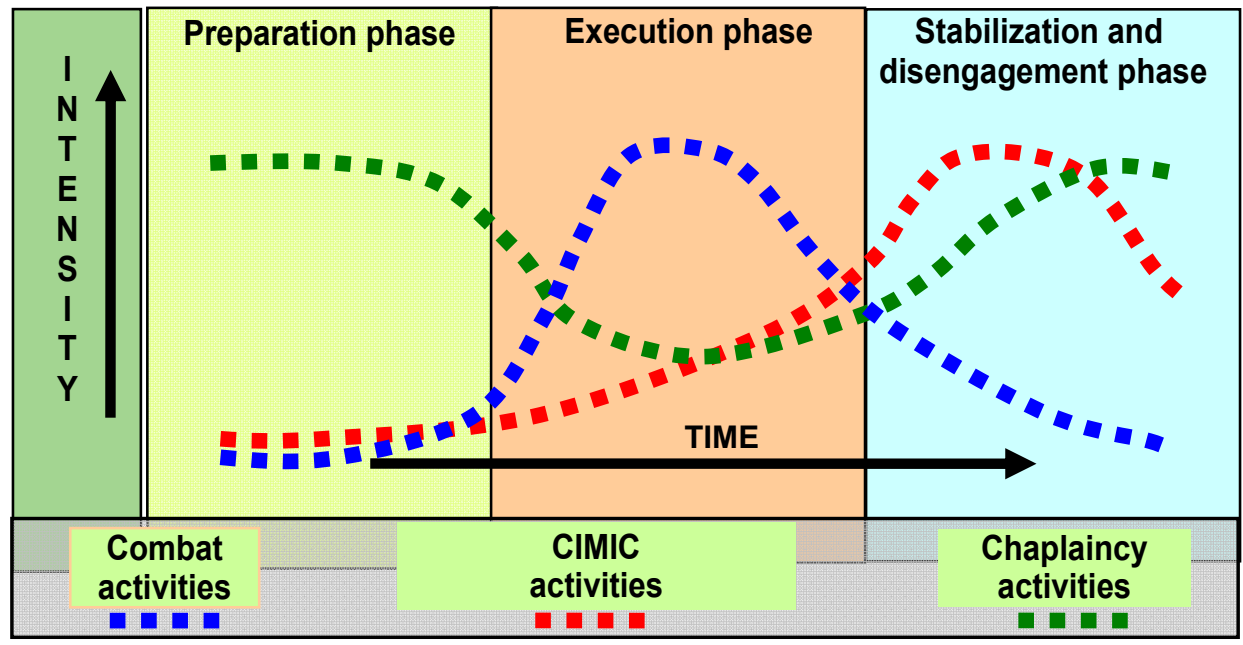

Picture 1 - Comparative review of intensity of combat activities, CIMIC activities and chaplaincy activities according to phases of combat operation 
It is clear that the third phase unlike previous two phases is rather non-combatant whereas the second one is characterized by a strong relation to the social dimension of operational environment. It is also known that the level of intensity of combat activities during a combat operation varies and it is minimal in the first phase. At the end of the first phase it begins to increase, and during the second phase it reaches its maximum. After that, the level of intensity of combat activities starts to decrease, so during the third phase of an operation it becomes similar to the level of the first phase. In CIMIC Doctrine of the Serbian Armed Forces it is written, inter alia, that the intensity of CIMIC activities is inversely proportional to the intensity of combat activities, and it reaches its maximum in the third phase of operations. ${ }^{4}$ When considering chaplaincy activities during phases of combat operations it is noticed that their intensity during the first and third phase is very high whereas during the second phase it is at a lower level. Otherwise, chaplaincy activities are classified into two groups: 1) worship and religious rites and 2) other religious activities. ${ }^{5}$ The degree of inverse proportion of the intensity of combat and chaplaincy activities during combat operations is even more expressed. It can also be concluded that the intensity level of CIMIC activities and chaplaincy activities in the third phase of operations is almost the same. Thus, the possibility of the future unique regulation of overlapping fields of the aforementioned activities is offered as a special challenge. The second analysis is related to the intensity of chaplaincy activities according to phases of combat operations. Before considering certain issues from the field of their execution, it is necessary to emphasize that in the first and third phase of operations the intensity of execution of worship and religious rites and other religious activities is inversely proportional. Actually, the intensity of worship and religious rites is somewhat lower in the first and third phase whereas it reaches its maximum in the second phase. The situation is opposite with other religious activities and the intensity of its execution is higher in the first and third phase whereas in the second phase it is somewhat lower (Picture 2).

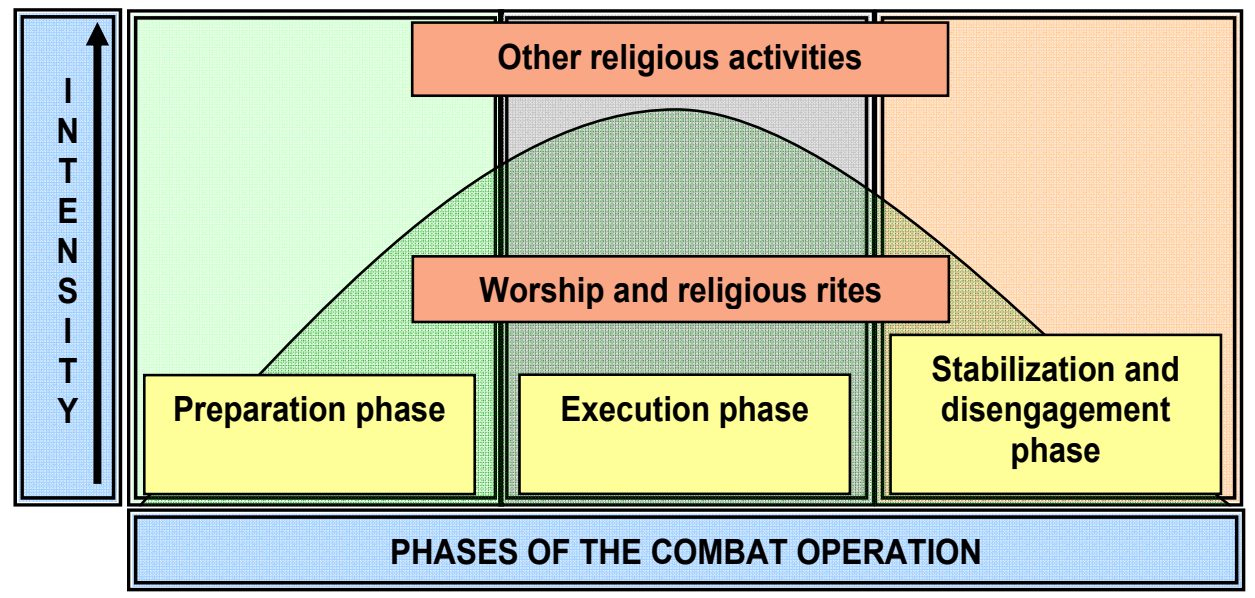

Picture 2 - Comparative review of intensity of worship and religious rites and other religious activities according to phases of combat operations

\footnotetext{
${ }^{4}$ CIMIC Doctrine of the SAF, Media Centre „Odbrana”, Belgrade, 2012, p. 30.

${ }^{5}$ Regulation on the chaplaincy in the SAF, Official Gazette of the Republic of Serbia, No. 22/11, Article 22.
} 
Influence of Chaplaincy on Preparation and Execution of Operations

The aforementioned is a consequence of the effect of several factors. These are: the intensity level of combat operations, characteristics of an armed conflict and duration of an operation, and the influence of the time dimension of operational environment can be noticed, as well. It has already been stressed that the level of intensity of combat activities is the highest in the second phase, which has a crucial effect on the fact that worship and religious rites in this phase is not only more intensive, but also more prevailing, so in relation to other religious activities during execution phase it has a higher level of priority. The reasons are in more expressed presence of danger, stress and chaos, and in sudden changes of situation and great increase in number of events in a unit of time as a result of conduct of combat activities such as wounding and death as being the most dramatic ones. However, this does not mean that, in accordance with the possibilities, necessity and available time, other religious activities would not be conducted in this phase.

The time dimension of operational environment during execution phase of combat operations exerts an influence on the increase of priority level of worship and religious rites in relation to other religious activities. During execution of operations time represents a complex value and encompasses several intervals, which have their beginning, flow and end. The total duration of operations is considered in relation to phases of an operation and consists of: the time for preparation, the time for execution of an operation and the time for stabilization of fulfilled objectives and disengagement of a unit. ${ }^{6}$ The time for execution of an operation includes the initial and execution time for conduct. The initial time represents an interval from receiving a task until starting its execution whereas the execution time is from beginning of execution until conduct of a specific combat task. ${ }^{7}$ The length of the aforementioned intervals depends on numerous factors. However, the execution time differs slightly, but sufficiently, from other intervals in lack of possibility, figuratively speaking, to "stop and go back". The issue of time, actually, from the theological point of view, is a category considered in a special way and a review from this point offers new and interesting remarks, which are not the topic of this paper. It means that, as a consequence of the expressed and already mentioned dramatic nature as a characteristic of the execution phase of combat operations in relation to it, according to an unwritten rule and again figuratively speaking, "there is more time" in the first and third phase. Although someone would think of it as being "psychological illusion", and someone else as "reality" due to characteristics of an armed conflict and more explicit needs of members of the armed forces, it affects the sudden increase in the intensity of worship in the execution phase of combat operations. The aforementioned statement is very important despite the fact that maximum attention is dedicated to preparation for execution of a combat operation. The intensity level of combat activities decreases in the third phase of a combat operation. In accordance with this, the number of requests to eliminate their consequences increases, which relates to chaplaincy activities to a considerable extent, as well. In other words, the consequences produced in the second phase are eliminated in the third phase, when the relationship to the killed, wounded and traumatized comes to the fore and the work with families of the armed forces members, which is greatly achieved by conduct of other religious activities. It means that during the third phase of an operation the connection of chaplaincy to the social dimension of operational environment comes more to the fore.

\footnotetext{
${ }^{6}$ Doctrine of the SAF Operations, Media Centre „Odbrana”, Belgrade, 2012, p. 46.

${ }^{7}$ Ibid., p. 47.
} 
The third analysis is related to the priority level of certain types of worship and religious rites during the execution phase of operations depending on whether we talk about combat or non-combatant operations. The aforementioned intensity is not always the same, that is, it is different in the greatest number of cases. During eliminating consequences of non-combatant threats in the execution phase of non-combatant operations, due to the nature of such threats, there are changes in requests of the Serbian Armed Forces members for chaplaincy activities. In other words, the intensity level of worship and religious rites decreases in relation to the intensity of other religious activities.

\section{Chaplaincy in preparation phase for execution of operations}

Preparation of operations lasts from the moment of receiving a task until the beginning of an operation, when processes of the work of headquarters at decision making and preparation of units, their development and bringing are conducted, an operational schedule formed and a sequence of other measures preceding execution of operations. They are conducted before and during execution of operations and they encompass planning operations, organization of forces, provision of necessary resources, training and operational development of forces. ${ }^{8}$ Chaplaincy activities are conducted in order to contribute to reaching the required level of operational capabilities of forces engaged in an operation. The focus of engagement of military chaplains is on human resources, primarily on their qualitative characteristic, that is, the most vulnerable, the most prone to sudden changes and for an enemy the least known the moral component of the military strength. The justification and need for the aforementioned engagement is noticed in the fact that the armed forces members during operations are in the situation that, in the conditions of great psychophysical stress, they perform complex tasks. Therefore, preparation for operations carried out by military chaplains lasts continuously. It means they continue conditionally with preparation after the end of the first phase of operations, in the second and even third phase of operations. Such approach has as the result classification into preparation before, during and after performance of a task. Preparation before performance of a task is conducted in accordance with specificity of an operation and it has already been stated that in this case other religious activities prevail. Preparation during performance of a task is conducted in order to maintain spiritual strength of the armed forces members, who are already engaged in operations, which includes participation of military chaplains in operations, where, as already mentioned, worship and religious rites prevails. Preparation after performance of a task is based on activities conducted in order to stabilize the spiritual state of the disengaged personnel, where other religious activities come again to the fore.

\section{Participation in human resources preparation}

Preparation of human resources includes: human resources planning, calling up military conscripts, admission of professional members, deployment, socialization, moral and psychological preparation, career planning, resolution of status issues, evaluation and assessment of

\footnotetext{
${ }^{8}$ Ibid., p. 55.
} 
efficiency and capabilities of personnel. ${ }^{9}$ Chaplaincy has exceptional possibilities in eliminating negative effects of operations such as danger, stress, chaos and friction. Therefore, from the aspect of engagement of military chaplains in human resources preparation, moral and psychological preparation in which they participate are prioritized and done in cooperation with officers responsible for moral and psychologists. ${ }^{10}$ However, besides cooperation, it is the fact they exert a remarkable influence on shaping the overall moral profile of the armed forces members, mainly through enhancement of both motivational and ethical side of the moral component. The first one represents the will to fight and win, and the second one internalization of the ethical side of the moral component. ${ }^{11}$ Military chaplains primarily achieve this by affirmation of the ethical principles of religion and their simultaneous connection to the most important values of the military profession, which results in adoption of those values by the faithful armed forces members. They teach them to live according to the principles of religion and at the same time they prepare them for all difficult moments, which they will encounter in operations that they take part in together. In this way, the faith in victory and motivation for fight strengthen, as well as the ethical conduct during operations, which, inter alia, creates the favourable conditions for respect of the international humanitarian law provisions.

One of other religious activities is the engagement in preparation for execution of complex tasks, as well as taking measures to prevent extraordinary events, bad behaviour and negative phenomena such as suicide, abuse of psychoactive substances, sects, theft, etc. ${ }^{12}$ It means that preparation, which has begun in regular peacetime conditions, continues during operations in all phases and with adaptation to conditions in the area of an operation. Negative phenomena, especially those events which happen suddenly are noticed during this preparation and eliminated. Thus, military chaplains, during preparation phase of operations continue with previously started participation in primary, secondary and tertiary prevention of extraordinary events, bad behavior and negative phenomena. The primary preventive work includes the engagement in prevention of occurrence, the secondary in early detection, and the tertiary preventive work in rehabilitation, that is, elimination of consequences of extraordinary events, bad behavior and negative phenomena, which have already happened. This is especially significant during execution phase of operations because the main efforts of the engaged forces, primarily commanding personnel, are focused on performance of set tasks in operations. In such situation, occurrence of some of the aforementioned negative phenomena would have much harder consequences for operational capabilities of the forces executing an operation in relation to their occurrence in peacetime conditions. The mental hygiene teams in units not only continue, but intensify their work during all phases of operations. ${ }^{13}$ It is also significant to mention prevention of suicide,

\footnotetext{
${ }^{9}$ Army Doctrine, Media Centre „Odbrana”, Belgrade, 2012, p. 41.

${ }^{10}$ Regulation on the chaplaincy in the SAF, Official Gazette of the Republic of Serbia, No. 22/11, Article 22., Paragraph 1, Indent 2, Sub-Indent 7, Point 1.

${ }^{11}$ Internalization represents a transfer of certain external norms to an internal, mental plan, which is later experienced as their own.

${ }^{12}$ Regulation on the chaplaincy in the SAF, general quote, Article 22, Paragraph 1, Indent 2, Sub-Indent 6.

${ }^{13}$ The primary mental hygiene teams have been established at all tactical level commands, the secondary teams in military medical centres, and the tertiary mental hygiene team at the Military Medical Academy. The primary teams are composed of a deputy commander, a doctor and a psychologist, and an operations officer, the Military Police officer and a command NCO. The teams follow and analyze the psychological and social status and psycho-physical strain of members of a unit. They are engaged in preparation for execution of complex tasks and they
} 
which represents a very important activity of military chaplains. Furthermore, special attention is paid to the fight against sects and cults in the military environment in preparation phase of operations due to the danger of their destructive and devastating actions, which can have a negative effect on preparation and execution of operations. Moreover, it is known to what extent drinking alcohol, abuse of psychoactive substances, as well as inclination to abuse, sexual harassment, gambling, theft and fight can affect execution of operations. During preparation and execution of operations commanders and officers commanding take measures to prohibit and sanction such and similar events whereas military chaplains primarily exert their influence on strengthening awareness of members of their damage.

\section{Participation in planning operations}

The military organization and chain of command are characterized by a high level of representation of planning as a process function. Military chaplains, according to the issues from the field of functional competence, take part in all forms of planning in the military, which is also related to definition of tasks and activities, whose execution enables freedom of religion during operations of their forces with respect of specificity of their status. In order to contribute to optimization of capabilities of planning, execution and support to operations and exercise of freedom of religion during their conduct, military chaplains participate in planning operations, which encompasses the integration of chaplaincy activities in joint efforts of different forces in all assigned missions and tasks in order to contribute to their successful conduct. In conditions of establishing personal staff groups or without them military chaplains perform tasks under the direct command of a commander and they cannot perform the role of a coordinator or specialist staff officers. Furthermore, they cannot be engaged in intelligence preparation of battlefield, definition of performed and main tasks, preparation of an operational model and formulation of a mission statement, development of a commander's idea, elaboration, comparison and analysis courses of actions and definition of centres of gravity. However, they can exert an influence on definition of restrictions and risk assessment in operations and identification of facts and assumptions. Their engagement in the assessment of available forces is particularly important. Moreover, it is necessary that during orientation phase they have the results of the work of the teams for target selection not to affect their choice, but only to give their opinion which of considered targets should not be in a list. Thus, chaplaincy makes a contribution to eliminate possibilities for potential breach of the international humanitarian law provisions and fulfillment of one more condition that the social dimension of operational environment should be favourable, and that is legitimacy of the selected targets. During the phase of drafting documents military chaplains take part in creating appendices about human resources with operational order and they are responsible for drafting the point about religious issues.

propose measures to commanders to eliminate conditions, which may lead to extraordinary events and elimination of consequences of extraordinary events, which have already happened. They pay special attention to members with already noticed problems. The teams perform an advisory role. They have regular meetings and keep records of their work. Military chaplains, should be included in the mental hygiene teams. 


\section{Participation in training}

In order to strengthen the military collective, spiritual and moral values and motivation of the armed forces members, cherishing their military virtues and patriotism, as well as developing civil responsibility, military chaplains during preparation phase of operations participate in training of their members through organization of lectures and talks on spiritual and moral topics. ${ }^{14}$ The aforementioned practice can be conducted in two ways: according to the principle of obligatory content and the principle of volunteerism. The obligatory content of training is conducted in the form of preparation for the upcoming tasks in operations with the focus on training for adequate behavior in concrete religious environment. Due to the sensitivity of the topic military chaplains of the confession that in the area of an operation prevails with local population are engaged. This type of training should be obligatory for all members of the armed forces, who participate in operations, especially in multinational operations. Furthermore, one of the regular peacetime topics of training, which is intensified in commands, units and institutions during preparation phase of an operation, is internalization of the values of the military profession. The objective is to reach the defined ethical norms of behavior and thus turn the mentioned values into personal virtues of the armed forces members. During preparation phase of operations military chaplains are engaged in delivering lectures on the subject matter, but only for members of their confession. Thus, one of the obligations defined by the Code of Honour is performed. ${ }^{15}$ Training according to the principle of volunteerism is conducted with the focus on the engagement of military priests on covering issues from the field of relation between religion and war, faith and morals, and behaviour in concrete situations during operations, which, in this case, is related exclusively to members of their confession.

\section{Chaplaincy in execution phase of operations}

During execution phase of operations the planned forces carry out the assigned mission and at the same time chaplaincy activities is conducted, which directly contributes to execution of an operation with optimal manner of engagement of its resources. Commanders are the only ones who have the capacities of chaplaincy in operations at their disposal. The coordination of the work of military chaplains within chaplaincy is carried out according to the staff-functional line. Furthermore, one should not ignore and neglect canonical responsibility to the traditional church, that is, religious community which military chaplains belong to. It has already been emphasized that, in difference to preparation phase and stabilization and disengagement phase, worship and religious rites during execution phase of operations has greater intensity. Therefore, one of the following issues should consider this, as well.

\footnotetext{
${ }^{14}$ Regulation on the chaplaincy in the SAF, general quote, Article 22, Paragraph 1, Indent 3, Point 1.

${ }^{15}$ Code of Honour of the SAF members, Official Military Gazette", No. 29/10, Article 8, Paragraph 1.
} 


\section{Chaplaincy in function of command and control}

On the basis of specificity of their status military chaplains during execution phase of operations perform the function of an adviser to a commander on religious, moral and motivational issues of members of a unit, which affect the success of an operation. ${ }^{16}$ They perform the function of personal staff officers at all levels of command with the possibility to have direct contact with a commander, and what is very important to stress, without mediators in considering sensitive theological issues. They are under the commander's direct control and without possibility to be subordinated to other staff officer. As personal staff officers they organize chaplaincy activities within his thoughts and by exerting feedback on the ethics of decisions, as well as preservation of humanitarian aspects of command and control during execution phase of operations. On the basis of the guidelines of commanders they inform other staff officers and officers in subordinate units, coordinate and monitor preparation and execution of planning processes within their functional responsibility. They perform the function of command only with their assistants. It is significant to emphasize the need that military chaplains should not propose members of the armed forces, who stand out during operations, for stimulating measures. When it comes to disciplinary measures and measures in responsibility of military disciplinary and civil courts, they cannot make statements in relation to taking measures against the armed forces members, which also includes the engagement in the function of a juror. Moreover, they cannot be engaged in conduct of inquest or investigation except in the field of Canon law and traditional church autonomy law, that is, religious community regarding worship and liturgical rites in subordinate commands, that is, institutions. During operations military chaplains provide commanders with observations on the issues of exercising freedom of religion, as well as potential violations of the Code of Honour provisions. Furthermore, they propose the appropriate measures without stating data, facts and circumstances which they come by during conduct of the Christian sacrament of Confession, which may reveal the identity of a person who has made a confession. Through the function of a commander's adviser military chaplains take care that during operations all members who wish so can exercise the right to freedom of religion guaranteed by the Constitution and law. Military chaplains exert an influence on command in order to prevent, detect and eliminate potential harassment, discrimination or privileges of other people due to their religious beliefs and belonging or not belonging to the church, that is, religious community. It also means detection and prevention of potential attempt of coercion, which would be used to make individuals state their confession and religious beliefs or their absence. Furthermore, one of the activities conducted by military chaplains in the function of a commander's adviser is taking measures to eliminate procedures and statements of the armed forces members, which are offensive to religious feelings of others including cursing and use of rude language about religious values, which are sacred for believers, as well as the attempt to carry out activities with the objective to influence other people to change religion. All these activities can be considered as regular peacetime tasks. However, during execution of operations, due to characteristics of an armed conflict, they become increasingly important. One of the

\footnotetext{
${ }^{16}$ Regulation on the chaplaincy in the SAF, general quote, Article 14, Paragraph 1, Indent 3.
} 
other religious activities is monitoring and control of the work in subordinate units. ${ }^{17}$ In this sense, they control the level of undertaken measures in the field of organization of exercising freedom of religion of the armed forces members, creation of conditions for chaplaincy activities during operations, respect of the prescribed time, structure and chaplaincy and liturgical rites practice in the correct manner, level of the cooperation with military chaplains of the same rank and local priests, as well as keeping the prescribed documentation and material records. Moreover, they also consider potential attempt of making military chaplains practice worship and religious rites which are contrary to the autonomous regulations of the church, that is, religious community they belong to, cases of their disruption and the attempt to stop them, or holding them responsible by a superior officer for the manner in which they practice worship and religious rites, as well as all other potentially expressed activities, which would hinder the structure and autonomous regulations of traditional churches and religious communities. The methodology of conducting control, which is actually intensified during preparation phase of operations is in accordance with by-laws, which have defined this field in the Serbian Armed Forces.

\section{Worship and religious rites in operations}

Military chaplains carry out worship and religious rites exclusively in compliance with autonomous regulations of traditional churches and religious communities whereas by-laws stipulate only conditions for their conduct, not the manner. The conditions are principally the same during execution of all assigned missions and tasks, without difference in circumstances. However, the area of operation represents in a certain sense specific environment. Therefore chaplaincy and liturgical rites during this phase are carried out in specific conditions, although according to the manner of officiating there is no deviation in relation to provisions of the autonomous regulations of traditional churches and religious communities, as well as conditions for their conduct in the Serbian Armed Forces, which has already been stipulated by the by-law regulation. Actually, the internal structure and organization of traditional churches and religious communities cannot be affected by chaplaincy and liturgical rites practice. Military chaplains practices liturgical rites in peacetime conditions only in an exceptional situation or with special consent of traditional church, that is, religious community they belong to. Worship during execution phase of operations represents an exceptional situation. The requests for funeral and the Christian sacraments of baptism, anointing and marriage during operations can serve as an example. It means that during funeral of the armed forces members of the Orthodox confession the military priest can do requiem in regular circumstances in accordance with a wish of the family of the deceased and ex officio, but with the consent of a local priest. However, the specificity which characterizes execution phase of operations due to great dynamics and characteristics of an armed conflict does not allow time for getting special consent, and they can be considered to be exceptional situations. In such case, at the end of operation, military priest subsequently regulates administrative issues in relation to the structure and organization of church. However, during operation he is mainly engaged in practicing chaplaincy and litur-

\footnotetext{
${ }^{17}$ Ibid., Article 22, Paragraph 1, Indent 2, Sub-Indent 7, Point 5.
} 
gical rites which demand consent in regular circumstances. The situation is interesting when it comes to the Christian sacrament of Communion, which military priests practice during the Holy liturgy. It can be practiced for the sick people, who are not capable of participating in the Holy liturgy, as well as for the dying according to a special procedure. However, during combat operations such type of practicing the Christian sacrament of Communion is common, especially with high dynamics of combat activities and dangerous situation with high mortality rate of participants. In such conditions, besides requiem, military priests spend the greatest amount of time on practicing the Christian sacraments of Confession and Communion.

\section{Chaplaincy and CIMIC}

CIMIC is the function which links and coordinates activities between the armed forces and various participants in civil environment in order to create conditions for support to missions in peacetime, state of emergency and war. ${ }^{18} \mathrm{CIMIC}$ is the content of combat activities, which is planned, organized and performed in all operations of the Serbian Armed Forces. ${ }^{19}$ The effects of CIMIC are not decisive in operations. However, they affect their result and reaching the set goals. The social dimension of operational environment in which an operation is executed exerts a special influence on CIMIC. It can be concluded that it connects two functions of the defence system during operations (CIMIC and religious) to a certain extent. The connection between the armed forces and actors of environment is especially emphasized according to CIMIC function whereas chaplaincy is primarily focused on its own armed forces. However, an element of CIMIC is the support to its own forces whereas chaplaincy can be practiced within CIMIC activities. In other words, military chaplains can be engaged, if the situation requires and allows so, for the needs of CIMIC teams and centres in the area of an operation according to the order of the force commander. This shows not only the interaction between chaplaincy and $C I M I C$, but also the perspective of further development of their joint engagement. The scope of the engagement of total military resources in conduct of CIMIC activities depends on whether operations are combat or non-combatant.

Combat operations are characterized by the high intensity of activities, which engage all available resources of the armed forces to the maximum. Therefore, focus of the forces on execution of combat tasks leaves less possibility for their engagement for CIMIC needs. ${ }^{20}$ However, CIMIC activities in non-combatant operations are broader and more complex than in combat operations. The limited military resources, greater presence of media, expectations of local and international community, a high number of international, governmental and non-governmental organizations, everyday relations with local population and other civil authorities will be of key importance for conduct of $\mathrm{Cl}$ MIC. $^{21}$ The type of chaplaincy activities, which will be included in performance of CIMIC

\footnotetext{
${ }^{18}$ CIMIC Doctrine of the SAF, general quote, p. 10.

${ }^{19}$ Ibid., p. 27.

${ }^{20}$ Ibid., p. 30.

${ }^{21}$ Ibid., p. 32.
} 
tasks, depends mainly on whether operations are combat or non-combatant. It has already been said that during execution phase of combat operations the requests of their participants for worship and religious rites are more expressed. However, chaplaincy during execution phase of non-combatant operations is available to less degree than in execution phase of combat operations, which creates conditions for strengthening the intensity of the other religious activities, and their inclusion in CIMIC activities.

Worship and religious rites can be practiced within CIMIC during operations. However, the other religious activities have much greater significance in CIMIC activities. The aforementioned social dimension in the area of an operation is defined by actors of civil environment such as: population, authorities, companies, international, non-governmental and religious organizations, groups and associations. The population, international, governmental and religious organizations, groups and associations come to the fore as actors which have more expressed interaction with chaplaincy during operations, that is, chaplaincy exerts a greater influence on their preparation and execution through them. Thus, during operations one of the other religious activities of chaplaincy comes especially to the fore collaboration with local priests. Chaplaincy in coordination with organizational elements in charge of CIMIC also exerts a positive influence on execution of operations by engagement in the activities of providing assistance to civil authorities during evacuation of people and material resources, rendering humanitarian assistance and all other measures which influence the provision of basic living needs. It is significant that in such cases military chaplains of the same confession that local population belongs to are engaged.

\section{Chaplaincy in stabilization and disengagement phase}

Stabilization and disengagement phase represents the phase of an operation in which, after reaching the objective of the operation, a political solution of a problem is considered, as well as elimination of consequences produced during execution of the operation. $^{22}$ Stabilization and disengagement phase can last differently and depends on a level of operations, their type, period of an armed conflict and a great number of conditions, which define the desirable end state. During this phase, and in compliance with the reached degree of stabilization and disengagement, besides the disengaged personnel of its units, activities of military chaplains can gradually start to include members of their families, as well. The interaction between CIMIC and chaplaincy from execution phase of operations continues to exist even after its end. More precisely, it reaches its fullness in stabilization and disengagement phase, which completes a wide range of positive effects of chaplaincy on operations. In absence of local priests, military chaplains can practice chaplaincy for the needs of local population, especially in emergencies, but exclusively for the confession they belong to under condition that they do not affect the structure and internal organization of church, that is, religious community. In cooperation with governmental organizations, churches and religious communities and logistics authorities, they can also be engaged from the expert advisory aspect in the infrastructural reconstruction of religious facilities damaged in operations, but once again exclusively within confession

${ }^{22}$ Army Doctrine, general quote, p. 107. 
they belong to. In order to eliminate consequences with local population caused by execution of operations, military chaplains may collaborate with doctors and psychologists by conducting certain activities.

\section{The work with members of the Serbian Armed Forces and their families}

In order to solve problems caused by participation in operations, military chaplains render assistance to their members, as well as members of their families by carrying out the pastoral and advisory work. ${ }^{23}$ It is done in cooperation with military psychologists in order to render psychological assistance on spiritual bases by integration of faith healing and contemporary psychology and psychotherapy. This manner of their engagement as certain spiritual improvement of secular psychological understanding and solving problems of the armed forces members and members of their families is focused on eliminating consequences of stress, fear, post-traumatic stress disorder, depression, grief caused by farewells and loss and psychological problems, which arise in operations. During the pastoral and advisory work military chaplains pay special attention to the dying members and the heavily wounded. The pastoral consultancy is organized during all phases of operations. However, the maximum of its influence is reached in stabilization and disengagement phase. Due to the nature of their occupation and characteristics of an armed conflict, it is necessary that military chaplains know the basis of psychological sciences and the nature of the human psyche, and to have constant collaboration with military psychologists, who are responsible for psychological work in the Serbian Armed Forces. It is significant having in mind that a man is a three-layer being composed of the soul, body and spirit, and the pastoral and advisory work is exactly focused on the field of the human soul. Contemporary research of the level of trauma and post-traumatic reaction experienced by people and manifested in different ways shows that level does not depend on gender or age, which means there is no the armed forces member who can be "immune" to post-traumatic stress disorder during operations regardless of the position in hierarchy. ${ }^{24}$ The specificity of the Christian sacrament of Confession is that it draws a clear line in responsibilities and possibilities of military priests on the one hand and military psychologists on the other hand. Members of the armed forces - Christian believers know that priests have been given the spiritual authority through the Christian sacrament of ordaining to dispel people from sin, and that no one else can have such authority, not even psychologists. The confession, that is, repentance during operations, inter alia, represents a very efficient cure for a believing traumatized member of the armed forces. If he still experiences desperation, the feeling of helplessness and especially strain of consciousness after confession, the military chaplain then sends him to the military psychologist. Actually, it means that in the concrete case we have loss of the

\footnotetext{
${ }^{23}$ Regulation on the chaplaincy in the SAF, general quote, Article 22, Paragraph 1, Indent 2, Sub-Indent 8.

${ }^{24}$ Adjustment disorder in combination with anxiety and depressive behavior can include sleep difficulties, a high level of irritation and anger, difficulties in general functioning and concentration while working and doing everyday work, the increased level of alertness in the form of general excitability (great excitement), great fear, a high level of anxiety, a low level of tolerance to frustration and physiological reaction to events which symbolize or remind of a traumatic experience.
} 
faith and doubt in the Christian sacrament. Therefore, besides confession, it is necessary to carry out therapy. In addition, in the situation when there is no a psychologist in the vicinity, and his urgent engagement is necessary, which is the common case in operations, military chaplains should be ready to conduct the first phase of pastoral approach. ${ }^{25}$ Everything that is said in relation to the pastoral and advisory work with the armed forces members is completely applicable to members of their families under the condition that the situation in the area of an operation enables it and that a unit of the traumatized one is meanwhile disengaged.

\section{Participation in R\&R programme}

Rest and recuperation (R\&R) programme is conducted in the full scope after the end of an operation, when forces are disengaged completely. However, certain topics can be covered in the final part of stabilization and disengagement phase or in the part of the area where an operation is not executed any more. Chaplaincy takes part with its activities in R\&R of the armed forces members. If conditions in the area of an operation permit, visits to sacred places of spiritual importance for their confession can be organized for the disengaged members in free time, and the military cemeteries and places of suffering of members of our armed forces throughout history. The aim is to provide conditions for stabilization of the mental state of the armed forces members through prayers and spiritual content. During R\&R period there is more intensive practice of thanksgiving and memorial service (requiem, mass of the dead and rahmah) to the members killed during execution of operations and the Christian sacraments of Confession, Confirmation and Anointing. Besides worship and rites, the pastoral and advisory work is continued and military chaplains are engaged in the work of the mental hygiene teams. In addition to chanting, during chaplaincy and rites church choirs can perform in the events of cultural character in the part of the area where an operation in no longer executed, which is also significant for the moral component of its military strength.

\section{Conclusion}

Chaplaincy represents a strong cohesive factor with the possibility of a simultaneous impact on strengthening each of three components of the military strength separately and their mutual connection, which indicates its significance for the total military strength

\footnotetext{
${ }^{25}$ It encompasses a group work with the traumatized. In the beginning they are explained that what they feel in most cases can be "normal" (so-called intervention of normalization), and not pathological. The objective is that the traumatized Army members accept there are ways to overcome a problem or at least "deal with it" without a psychotherapist. Therefore, here we talk about certain psychological "first aid", where a group of the traumatized without psychologists or psychotherapists can begin the process of relief and discussing problems with the military priest, that is, assistant priest. In this manner the problem will be later in work "metabolized" more easily, accepted, discussed, revealed and overcome. The point of the mentioned group work is to encourage the traumatized to express their pain, shock, anger or other content which follows the problem of the post-traumatic stress disorder, which is, of course, run in parallel with prayers and spiritual content of chaplaincy.
} 
of the Serbian Armed Forces. The influence of chaplaincy on the moral component of the military strength is the most comprehensive and the most important. The moral component of the military strength is based, inter alia, on the moral principles and the most significant values of the military profession proclaimed in the Code of Honour. By compliance with the norms resulting from these values and preserving them at the same time, conditions are created for a member of the Serbian Armed Forces to accept the aforementioned values and turn them into personal virtues.

It can be concluded that the capacities of chaplaincy in eliminating danger, stress, chaos and friction during operations are remarkable. During contemporary operations chaplaincy activities are conducted in conditions of rather multidimensional operational environment. The type and intensity of those activities depend to a great extent on the social and time dimension of operational environment, types and phases of operations, the scope of activities and CIMIC actors. The level of intensity of chaplaincy and CIMIC activities is almost the same in stabilization and disengagement phase, which creates conditions for opening a new chapter of the future simultaneous theoretical considerations of the mentioned field. Chaplaincy in coordination with organizational elements in charge of CIMIC can exert a positive influence on execution of operations by engagement in the activities of providing assistance to civil authorities during evacuation of people and material resources, rendering humanitarian assistance and all other measures which influence the provision of basic living needs. It is significant that in such cases military chaplains of the same confession that local population belongs to are engaged. The social dimension of operational environment in which an operation is executed exerts a special influence on CIMIC. It can be concluded that it connects two functions of the defence system during operations (CIMIC and religious) to a certain extent. Explication of chaplaincy in planning, preparing and executing operations, and other similar topics which are used to consider different aspects of operations and chaplaincy simultaneously, exerts undoubtedly a positive influence on the development of the operational art as one of the defence sciences.

Having in mind that military chaplains at an operational and tactical level are directly subordinated to commanders, it is necessary to improve modalities of their cooperation with officers responsible for moral and psychologists within the groups formed in the commands of the forces executing an operation by upgrading the by-law regulation, which defines operational planning in the Serbian Armed Forces, as well as by development of standard operating procedures. Furthermore, from the aspect of the engagement of the resources which chaplaincy has at its disposal, it is necessary to upgrade the set of doctrinal documents in the field of operations, service, CIMIC and human resources management doctrines.

In order to use the capacities of chaplaincy in operations to the maximum, there should be no coercion when it comes to chaplaincy because it is defined according to the principle of volunteerism, that is, religious content can be practiced exclusively on the basis of personal beliefs of the Serbian Armed Forces members. Moreover, during planning, preparing and executing operations, making a compromise in relation to specificity of military chaplains should not be allowed. Despite being the Serbian Armed Forces officers, they can have non-combatant status, which applies not only to prohibition of carrying and using weapons, but to several other stipulated specific things. Chaplaincy 
can only in this manner exert a positive influence on planning, preparing and executing operations. Otherwise, disrespect of such specificity would cause numerous problems: violation of the Geneva Convention provisions, lack of capacity to counter religious extremism, even its favouring, disharmony in relation between command and control and canonical provisions, interference of military chaplains in command without responsibility, and commanders in canonical issues, support to proselytism, etc. In order to create conditions for a comprehensive positive influence of chaplaincy on planning, preparing and executing operations, and having in mind that chaplaincy in the Serbian Armed Forces has recently been established (introduced again), it is necessary to invest efforts to enhance the level of competence of military chaplains as staff officers.

Taking into account characteristics of contemporary conflicts, a high level of dynamics that characterizes modern operations, a wide range of potential actions and abundance of the spiritual capacities which traditional churches and religious communities have at their disposal from dogmatic aspect, and rather high percentage of the Serbian Armed Forces members who are believers, it can be concluded that chaplaincy has exceptional possibilities to exert a positive influence on planning, preparing and executing operations.

\section{Literature}

[1] Stevica S. Karapandzin, Chaplaincy in SAF, influence on Army operations, Media Centre „Odbrana”, Belgrade, 2015;

[2] Doctrine of the SAF operations, Media Centre „Odbrana”, Belgrade, 2012;

[3] Army Doctrine, Media Centre „Odbrana”, Belgrade, 2012;

[4] CIMIC Doctrine of the SAF, Media Centre „Odbrana”, Belgrade, 2012;

[5] Code of Honour of the SAF members, „Official Military Gazette”, No. 29/10; $22 / 11$

[6] Regulation on the chaplaincy in the SAF, Official Gazette of the Republic of Serbia, No.

[7] Guide for operational planning and work of commands in the Serbian Armed Forces, Serbian Armed Forces General Staff, Planning and Development Department (J-5), Belgrade, 2013;

[8] Convention (III) relative to the Treatment of Prisoners of War. Geneva, 12th August 1949., http://www.icrc.org/ihl//NTRO/375?OpenDocument, Internet, $8^{\text {th }}$ March 2014. 
Attachment 1

\section{PRIORITIES IN EXECUTION WORSHIP AND RELIGIOUS RITES DURING PREPARATION AND PERFORMING OF COMBAT OPERATIONS}

\begin{tabular}{|c|c|c|c|}
\hline \multirow[b]{2}{*}{ ACTIVITY } & \multicolumn{3}{|c|}{ PHASES OF OPERATION } \\
\hline & $\begin{array}{l}\text { Prepa- } \\
\text { ration }\end{array}$ & $\begin{array}{l}\text { Exe- } \\
\text { cution }\end{array}$ & $\begin{array}{l}\text { Stabiliz. } \\
\text { and } \\
\text { diseng. }\end{array}$ \\
\hline 1 & 2 & 3 & 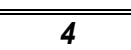 \\
\hline Chaplaincies (Holy Liturgy, Holy Mass, Jummah) & & & \\
\hline $\begin{array}{l}\text { Daily Religiouss Services (Vespers, Orthros, Daily } \\
\text { Mass, Islamic Daily Prayers) }\end{array}$ & & & \\
\hline $\begin{array}{l}\text { Holy Sacraments (The Eucharist, Baptizm, Chrisma- } \\
\text { tion, Marriage, Confession, Communion, Tewba, Sharia } \\
\text { Wedding) }\end{array}$ & & & \\
\hline Special Services and Blessings & & & \\
\hline Anointing of the Sick & & & \\
\hline Memorial Services & & & \\
\hline Funnerals & & & \\
\hline Ordination (Priests, Chaplains, Imams, etc.) & & & \\
\hline
\end{tabular}

\section{Legend:}

\begin{tabular}{|c|c|c|}
\hline $\begin{array}{l}\text { Higher level } \\
\text { of priority }\end{array}$ & $\begin{array}{l}\text { Medium level } \\
\text { of priority }\end{array}$ & $\begin{array}{l}\text { Lower level } \\
\text { of priority }\end{array}$ \\
\hline
\end{tabular}


Attachment 2

\section{PRIORITIES IN EXECUTION WORSHIP AND RELIGIOUS RITES DURING PREPARATION AND PERFORMING OF NON-COMBATANT OPERATIONS}

\begin{tabular}{||l|c|c|c||}
\hline \multicolumn{1}{|c|}{ ACTIVITY } & \multicolumn{2}{c|}{ PHASES OF OPERATION } \\
\cline { 2 - 4 } & $\begin{array}{c}\text { Prepa- } \\
\text { ration }\end{array}$ & $\begin{array}{c}\text { Exe- } \\
\text { cution }\end{array}$ & $\begin{array}{c}\text { Stabiliz. } \\
\text { and } \\
\text { diseng. }\end{array}$ \\
\hline \hline \multicolumn{1}{|c|}{$\mathbf{1}$} & $\mathbf{2}$ & $\mathbf{3}$ \\
\hline Chaplaincies (Holy Liturgy, Holy Mass, Jummah) & & \\
\hline $\begin{array}{l}\text { Daily Religiouss Services (Vespers, Orthros, Daily } \\
\text { Mass, Islamic Daily Prayers) }\end{array}$ & & \\
\hline $\begin{array}{l}\text { Holy Sacraments (The Eucharist, Baptizm, Chrisma- } \\
\text { tion, Marriage, Confession, Communion, Tewba, Sharia } \\
\text { Wedding) }\end{array}$ & & \\
\hline Special Services and Blessings & & \\
\hline Anointing of the Sick & & \\
\hline Memorial Services & & \\
\hline Funnerals & & \\
\hline Ordination (Priests, Chaplains, Imams, etc.) & & \\
\hline \hline
\end{tabular}

\section{Legend:}

Higher level
of priority $\quad \begin{aligned} & \text { Medium level } \\ & \text { of priority }\end{aligned} \quad \begin{aligned} & \text { Lower level } \\ & \text { of priority }\end{aligned}$


Attachment 3

PRIORITIES IN EXECUTION OTHER RELIGIOUS ACTIVITIES DURING PREPARATION AND PERFORMING OF OPERATIONS

\begin{tabular}{||l|c|c|c||}
\hline \multicolumn{1}{|c|}{ ACTIVITY } & \multicolumn{2}{c||}{ PHASES OF OPERATION } \\
\cline { 2 - 4 } & $\begin{array}{c}\text { Prepa- } \\
\text { ration }\end{array}$ & $\begin{array}{c}\text { Exe- } \\
\text { cution }\end{array}$ & $\begin{array}{c}\text { Stabiliz. } \\
\text { and } \\
\text { diseng. }\end{array}$ \\
\hline \hline \multicolumn{1}{|c||}{1} & 2 & 3 & 4 \\
\hline Operations Planning Process & & & \\
\hline Advising of Commanders on Religious matters subjects & & \\
\hline Lectures and Preaching ( Spiritual and Ethics Topics) & & \\
\hline Chapel Equipping and maintaining & & \\
\hline Supervising of Chaplains and Chaplains Assistants & & \\
\hline $\begin{array}{l}\text { Engagement in Preparation for the Execution of } \\
\text { Complex Tasks, in Emergency Prevention, Unaccepted } \\
\text { Behavior and Negative Phenomena Measures }\end{array}$ & & \\
\hline $\begin{array}{l}\text { Cooperation with Officers Responsible for Moral and } \\
\text { Psychologist }\end{array}$ & & & \\
\hline Cooperation with Chaplains and Local Priesthood & & & \\
\hline \begin{tabular}{l} 
Pastoral care (Army members and their families) \\
\hline
\end{tabular} & & & \\
\hline
\end{tabular}

\section{Legend:}
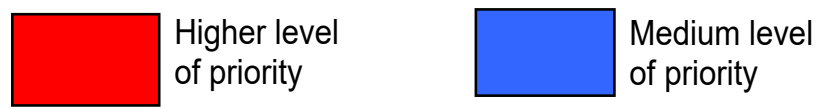

Lower level of priority 